\title{
Indonesian Couples' Pregnancy Ambivalence And Contraceptive Use
}

By Janine L. Barden-O'Fallon and llene S.Speizer

Janine L. BardenO'Fallon is director, MEASURE Evaluation Population and Reproductive Health, University of North Carolina, Chapel Hill, NC, USA. Ilene S. Speizer is research associate professor, University of North Carolina Gillings School of Global Public Health, Chapel Hill, NC, USA.
CONTEXT: Most studies on pregnancy ambivalence are based on data from women and depend on the women's perceptions to measure their partner's pregnancy intentions. Because these perceptions may not be accurate, data collected directly from men are needed to understand the role of couple dynamics in fertility behavior.

METHOD: Matched couple data from the 2002-2003 Indonesia Demographic and Health Survey were used to examine contraceptive use, fertility desires and attitudes about becoming pregnant in the next few weeks-whether it would be a big problem, a small problem or no problem. Concordance between partners on these issues was evaluated. Inconsistent fertility desires and responses to the problem question are used to define ambivalence within couples. Multivariate logistic regression analyses were used to assess whether couples' pregnancy ambivalence was associated with contraceptive use.

RESULTS: Seventy-one percent of husbands and 54\% of wives reported that a pregnancy in the next few weeks would be "no problem"; couples' concordance on this question was 64\% among contraceptive users and $61 \%$ among nonusers. In the multivariate analysis, couples who were discordant on the issue of a pregnancy in the near future had $26 \%$ lower odds of using contraceptives than couples in which both partners agreed a pregnancy would be a big or small problem. Contraceptive use was also less likely for couples in which one partner wanted to delay or stop childbearing and the other wanted more children or was undecided (odds ratio, 0.4).

CONCLUSIONS: Husbands and wives influence each other's fertility attitudes and family planning use. Both husbands' and wives' pregnancy attitudes should be taken into account at the time of screening and method selection. International Perspectives on Sexual and Reproductive Health, 2010, 36(1):36-43
Pregnancy ambivalence can be understood as vague or conflicting attitudes about fertility intentions, and may be manifested in inconsistency between stated fertility desires and contraceptive behaviors. Pregnancy ambivalence may be found among both contraceptive users and nonusers and occurs in countries with both high and low contraceptive prevalence. ${ }^{1,2}$ For example, women who are not using contraceptives but report that they want to delay or stop childbearing may be ambivalent about the next pregnancy; these women are often classified as having an unmet need for contraception and targeted for family planning services. These women may be ambivalent about contraception as well. ${ }^{3}$ Pregnancy ambivalence has also been described among women who become pregnant while using contraceptives but do not classify the pregnancy as unwanted or mistimed, as would be expected. ${ }^{1}$

Such findings suggest that conventional categories of pregnancy attitudes (wanted, mistimed or unwanted) may be oversimplified and do not account for ambivalence toward future pregnancies or the inability to form definite fertility intentions. ${ }^{4-6}$ As a result, ambivalent attitudes toward pregnancy or contraception may be biasing estimates of the proportion of women with unintended pregnancies or an unmet need for contraception. , $3^{2}$

Previous research from the United States has demon- strated that women expressing ambivalent attitudes about pregnancy are less likely to be current contraceptive users. When they use contraceptives, these women tend to use less effective methods and to use their chosen method less effectively. ${ }^{1,7-11}$ The inconsistent or ineffective use of contraceptive methods or the use of less effective methods can lead to negative health outcomes, such as unintended pregnancies and induced abortion. ${ }^{12-14}$ Thus, recognizing pregnancy ambivalence is important for family planning policy and programming efforts.

To date, most studies on pregnancy ambivalence are based on women's reports of family planning use and fertility desires; the overwhelming majority are from the United States, with a few from Sub-Saharan and North Africa. 1,2,7-11,15,16 When partners' pregnancy intentions are considered, it is the partner's perceived intentions, as reported by the woman, that are often used. ${ }^{8,17}$ However, we know that male partners influence family size decisions and contraceptive behavior in much of the world. ${ }^{17-22}$ According to a recent study from Bangladesh, for example, the predicted probability of contraceptive use was considerably lower among couples in which the husband wanted more children than among couples in which the husband wanted no more children. ${ }^{23}$ Also, in comparison with women, men have historically desired more chil- 
dren. ${ }^{24}$ It is therefore important to consider the role of male partners in studies of pregnancy ambivalence.

The objective of the current study is to address the above-mentioned gaps in the literature by using survey responses on contraceptive use and fertility desires from both husbands and wives to examine Indonesian couples' pregnancy ambivalence. We first look at how husbands and wives responded to the same questions on contraceptive use, fertility desires and whether a pregnancy in the next few weeks would be a problem for them. Next, we assess the proportion of husbands and wives who are ambivalent and the degree to which partners' fertility desires and pregnancy attitudes agree. This examination is done separately for couples who use contraceptives and those who do not. Finally, we assess the degree to which a couple's pregnancy ambivalence is associated with their current use of contraceptives. This final analysis examines the role of couple attitudes on use or nonuse of contraceptives.

\section{CONTEXT}

Given the country's total population of almost 220 million and its growth rate of nearly $1.5 \%$ per year, reducing Indonesia's population growth and fertility rates has been and continues to be a government priority. ${ }^{25}$ There is widespread support and use of family planning in Indonesia: In 2002-2003, 60\% of currently married women of reproductive age were practicing contraception; $57 \%$ of all married women were using a modern method. ${ }^{26}$ The proportion using any method is an increase of 10 percentage points from the 1991 rate of $50 \%{ }^{27}$

Although current use of modern methods in Indonesia is high, discontinuation and method switching are also common: Approximately 20\% of contraceptive users discontinue their method within the first 12 months of use; $2 \%$ do so because of method failure. ${ }^{26}$ High discontinuation may be partly explained by the fact that the most common contraceptive methods are temporary hormonal methods, such as the injectable ( $46 \%$ of all current users), oral contraceptives (22\%) or implants (7\%). ${ }^{26}$ Indonesian women also commonly express a desire for fertility control. Exactly half of all married women in the country aged 15-49 report not wanting any more children, while an additional 24\% would like to delay their next birth for two years or more. ${ }^{26}$ Women who do not want any more children are more likely to have had at least two children and to reside in urban areas than women who want more children. $^{26}$

Officially, abortion is illegal in Indonesia; therefore, incidence is difficult to ascertain. However, it has been estimated that one in five pregnancies end in abortion. ${ }^{28} \mathrm{Nev}$ ertheless, only $9 \%$ of currently married women are estimated to have an unmet need for family planning. ${ }^{26}$ Seventeen percent of births are estimated to be unintended (7\% unwanted at the time of conception and 10\% mistimed). The planning status of the birth is associated with birth order and age of the mother: Although almost all first births are wanted at the time of conception, $26 \%$ of fourth or higher order births are unwanted at conception. ${ }^{26}$ In addition, although fewer than $1 \%$ of women younger than 20 reported a birth as unwanted, this proportion increased to $38 \%$ for women aged $40-44$. It is estimated that the elimination of unwanted fertility in Indonesia would reduce the total fertility rate by $15 \%$, from 2.6 to 2.2 births per woman. ${ }^{26}$

\section{METHODOLOGY}

\section{Data}

The data for this study come from the 2002-2003 Indonesia Demographic and Health Survey (IDHS). ${ }^{26}$ The IDHS included a nationally representative sample of 29,483 ever-married women aged 15-49 and 8,310 currently married men aged $15-54$. The sample was derived through the use of a stratified two-stage procedure that considered provincial location and urban-rural classification. Response rates were extremely high; $98 \%$ of eligible women and $95 \%$ of eligible men were successfully interviewed. Most interviewed men (93\%) were married to an interviewed woman, thus a matched dataset containing 7,684 currently married couples was constructed.

The Indonesia survey is one of only a few Demographic and Health Surveys to ask both women and men whether a pregnancy in the next few weeks would be a big problem, a small problem or no problem, which is one of the questions used in this analysis to assess pregnancy ambivalence. Hereafter referred to as the "problem question," its specific wording was "In the next few weeks, if you discovered that you (your spouse) were pregnant, would that be a big problem, a small problem or no problem for you?" "Don't know" was not a response option. The analyses in this paper are based on the subsample of 5,061 couples in which both partners gave one of the three categorical responses to the question. The sample excluded all pregnant wives, infecund wives and sterilized husbands, as reported by self or spouse, and wives who reported that they were not currently having sex or who stated previously that they wanted a child "soon/now" or within two years. * The final sample of 4,993 couples was further reduced to exclude couples who were missing information for any of the key variables used in the analysis.

\section{Variables}

The variable for the problem question was coded dichotomously by assigning " 1 " to individuals who responded "no problem" and "0" to those who responded "small problem" or "big problem." We are thus comparing those who stated "no problem" with those who chose either of the other options. As a check, all analyses were run with the small problem group included in the no problem group (creating a dichotomous categorization of no or small problem vs. big problem) and we found that there were no changes in the results; this is likely because of the small number of individuals who responded "small prob-

*Unlike the women, all men were asked the problem question. 
lem." Other variables used in the descriptive analyses include current contraceptive use (yes or no) and fertility desires (want a child within two years, want to delay a birth for two or more years, want a child but are undecided when, want no more children and undecided). Ambivalence is defined as a response of "no problem" among individuals who reported wanting to delay a birth for two or more years or to stop childbearing.

The dependent variable for the multivariate analysis is wife's reported current contraceptive use (coded 1 for "yes" and 0 for "no"). The key independent variable for the multivariate analysis is the couple's pregnancy ambivalence, which is based on responses to the problem question among the subset of couples in which at least one partner wanted to delay or stop childbearing. Couples' pregnancy ambivalence has three categories: one partner ambivalent, both partners ambivalent or neither partner ambivalent (the reference category). Couples' fertility desire has four categories: One partner wants to delay childbearing, while the other wants to stop; one partner wants to delay or stop childbearing, while the other wants another child within two years or is undecided; both partners want to delay childbearing; or both partners want to stop childbearing (the reference category).

Women's demographic characteristics associated with contraceptive use are also included in the multivariate analysis. Age is categorized as 15-24, 25-34 and 35-49 (reference category); education is categorized as having none (reference category), primary, or secondary or higher; the number of children ever born is grouped as $0-1$, $2-3$ or $\geq 4$ (reference category); region is categorized as Java vs. all other regions (reference category); and the fivecategory household wealth index was collapsed into three categories, with the poorest two quintiles ("poorer" households) and the highest two quintiles ("wealthier" households) being compared with the middle quintile (reference category). Husband's data for age, education and children ever born, although not included in the multivariate analysis because of high collinearity with the corresponding female variables, are given for comparison purposes. In this analysis of couple influences on ambivalence, only the wife's report of contraceptive use is used, again because of high collinearity between the husband's and wife's reported contraceptive use.

\section{Analysis}

First, we assess patterns in and make comparisons between husbands' and wives' responses to survey questions on contraceptive use, fertility desires and the problem question. Responses to the problem question are presented in a cross-tabulation with fertility desires stratified by individual contraceptive use. This comparison allows us to examine the degree to which responses to the problem question vary by fertility desires, how these patterns compare between husbands and wives, and whether contraceptive users are more or less likely to be ambivalent about an unexpected pregnancy than nonusers.
TABLE 1. Percentage distributions of husbands and wives, by selected characteristics, Indonesia Demographic and Health Survey matched couple sample, 2002-2003

Characteristic

Husbands $¥$ Wives $¥$

Ag

$15-24$

$25-34$

$35-49$

$(\mathrm{N}=4,993) \quad(\mathrm{N}=4,993)$

Education

None

Primary

$\geq$ secondary

51.0

45.2

$(N-4,993)$

No. of children ever born

$0-1$

2-3

4.2

16.0

$64.4 \quad 46.6$

$\geq 4$

21.9

49.0

29.1

37.4

46.6

Household wealth

Poorer

Middle

Wealthier

\section{9}

21.1

39.0

6.2
54.7

54.7

39.1

Region

Java

All others

\section{8}

69.2

Current contraceptive use§

Yes

No

Don't know

74.5

24.3

1.3

76.4

23.6

Fertility desire

Wants child in $<2$ yrs.

Wants child in $\geq 2$ yrs.

Wants child, undecided when

Wants no more children

Undecided

$\begin{array}{rl}5.9 & \text { na } \\ 28.1 & 31.8 \\ 4.6 & \text { na } \\ 58.9 & 66.7 \\ 2.4 & 1.5\end{array}$

A pregnancy in the next few weeks would be...

$\begin{array}{lcr}\text { A big problem } & 19.3 & 36.8 \\ \text { A small problem } & 9.4 & 9.2 \\ \text { No problem } & 71.3 & 54.0 \\ & & \\ \text { Total } & 100.0 & 100.0\end{array}$

¥Sample excludes couples who did not respond to the problem question and couples with missing data on variables of interest. §For men: includes his report of wife's contraceptive use, plus his use of condoms, withdrawal or periodic abstinence. Notes: Proportions are weighted for survey design; Ns are unweighted. na $=$ not applicable.Percentages may not total 100.0 because of rounding.

Next, we assess the degree of concordance between husbands' and wives' responses on key variables of interest, including pregnancy ambivalence, using the Kappa statistic. The Kappa value for couple agreement is analyzed using the following scale: $<0$, poor agreement; 0-0.20, slight agreement; 0.21-0.40, fair agreement; 0.41-0.60, moderate agreement; 0.61-0.80, substantial agreement; and 0.81-1.0, almost perfect agreement. ${ }^{29}$ The relationships between variables in this and previous descriptive analyses are also examined using Pearson's chisquare at the 10,.05 and .01 levels of significance.

Finally, multivariate logistic regression is used to assess the degree to which pregnancy ambivalence expressed by one or both partners is related to contraceptive use as reported by the wife. To accomplish this, the sample is restricted to couples in which at least one partner reports 
wanting to delay a birth two or more years or to stop childbearing altogether and therefore may need to use family planning to attain this fertility desire. The sample excludes 79 couples in which wives were undecided about future childbearing and husbands wanted a child within two years, wanted a child but did not know when or were also undecided about childbearing.

The couples data are weighted using the sample weights provided by the IDHS; proportions presented in the tables are weighted, but sample sizes are not. All analyses were run using STATA statistical software, version 9.2.

\section{RESULTS}

Sixty-four percent of husbands and $47 \%$ of wives in our sample were aged 35-49 (Table 1). The mean age for husbands was 37.7 , and 33.3 for wives (not shown). Some $45 \%$ of husbands and $39 \%$ of wives had attained a secondary or higher level of education; only $4 \%$ of husbands and $6 \%$ of wives reported having no education at all. Because the study sample was restricted to nonpregnant, fecund couples, almost all the husbands and wives in the study sample had had at least one birth (99\%); about half of all respondents had two or three children. Given the coding scheme, about $40 \%$ of the couples were categorized as being in "poorer" households, 39\% in "wealthier" households, while $21 \%$ were in the middle socioeconomic status category. Close to one-third of the sample lived in Java.

About three-quarters of husbands and wives (75-76\%) reported currently using contraceptives. The majority of husbands and wives wanted to stop childbearing (59\% and $67 \%$ ), while slightly fewer than one-third wanted to delay childbearing for more than two years (28\% and 32\%). When asked whether a pregnancy in the next few weeks would be a big problem, a small problem or no problem, a large proportion of husbands (71\%) said it would be no problem, compared with $54 \%$ of wives. Conversely, $37 \%$ of wives reported it would be a "big problem," compared with 19\% of husbands. Only 9\% each of husbands and wives said a pregnancy would be a "small problem."

Cross-tabulation was used to examine consistency between contraceptive use and fertility desires (Table 2). Reported contraceptive use was higher among husbands and wives who wanted to delay a birth for at least two years

TABLE 2. Percentage of husbands and wives reporting contraceptive use, according to fertility desire

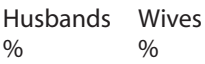

\section{Fertility desire**}

Wants child in $<2$ yrs.

Wants child in $\geq 2$ yrs.

Wants child, undecided when

Wants no more children

Undecided

$\%$

${ }^{* *} \mathrm{p}<$.01. Notes: Contraceptive use as reported by husbands and wives for respective cross-tabulations. Proportions are weighted for survey design; Ns are unweighted. na=not applicable.
TABLE 3. Percentage distribution of husbands and wives who report that a pregnancy in the next few weeks would be any problem or no problem, by fertility desire, according to contraceptive use

Contraceptive use and fertility desire

\begin{tabular}{lllll|l} 
& $\begin{array}{l}\text { Any } \\
\text { problem }\end{array}$ & $\begin{array}{l}\text { No } \\
\text { problem }\end{array}$ & $\begin{array}{l}\text { Any } \\
\text { problem }\end{array}$ & $\begin{array}{l}\text { No } \\
\text { problem }\end{array}$ & \\
\hline USERS & & & & & \\
Fertility desire** & & & 48.2 & 51.8 & 100.0 \\
All & 33.0 & 67.0 & na & na & 100.0 \\
Wants child in <2 yrs. & 1.3 & 98.7 & 30.1 & 69.9 & 100.0 \\
Wants child in $\geq 2$ yrs. & 19.0 & 81.1 & na & na & 100.0 \\
Wants child, undecided when & 24.4 & 75.6 & 53.7 & 46.3 & 100.0 \\
Wants no more children & 36.5 & 63.5 & 36.8 & 63.2 & 100.0 \\
Undecided & 33.0 & 67.0 & & & \\
NONUSERS & & & & & \\
Fertility desire** & & & 49.9 & 50.1 & 100.0 \\
All & 32.1 & 67.9 & na & na & 100.0 \\
Wants child in $<2$ yrs. & 2.0 & 98.0 & 29.8 & 70.2 & 100.0 \\
Wants child in $\geq 2$ yrs. & 19.7 & 80.3 & na & na & 100.0 \\
Wants child, undecided when & 14.4 & 85.6 & 53.9 & 46.1 & 100.0 \\
Wants no more children & 38.1 & 61.9 & 52.7 & 47.3 & 100.0 \\
Undecided & 9.9 & 90.1 & &
\end{tabular}

${ }^{* *} \mathrm{p}<$ <.01. Notes: Contraceptive use as reported by husbands and wives for respective cross-tabulations. Ns for husbands were 3,770 (users) and 1,223 (nonusers). Ns for wives were 3,830 (users) and 1,163 (nonusers). Proportions are weighted for survey design; Ns are unweighted. na=not applicable. Percentages may not total 100.0 because of rounding.

( $81 \%$ and $82 \%$, respectively) than it was for those who wanted to stop childbearing (75\% and $74 \%$ ). (This finding is likely the result of having only users of temporary methods in the sample since couples in which one partner was sterilized were dropped.) Husbands and wives who wanted to delay or stop childbearing and were using contraceptives were likely the most motivated to avoid a pregnancy. Conversely, individuals who want to delay or stop childbearing but are not using contraceptives are usually considered to have unmet need and targeted for family planning programs.

Next, we examined responses to the problem question in a cross-tabulation with fertility desires stratified by whether the individual reported being a user or nonuser of contraceptives (Table 3). Overall, for each category of fertility desire among users and nonusers, the proportion of husbands saying a pregnancy would be no problem was higher than the proportion of wives. Interestingly, contraceptive users, presumably those most interested in avoiding pregnancies, were no more likely than nonusers to report that becoming pregnant soon would be any problem except for husbands and wives who were in the "undecided" category and husbands in the "wants child, undecided when" category. In contrast with comparisons by contraceptive use status, comparisons by fertility preferences yield more intuitive patterns: The proportions of husbands and wives reporting no problem were highest for husbands wanting children in the next two years, lower for husbands and wives who wanted to delay, and lowest for husbands and wives who wanted no more children. However, pregnancy ambivalence was high even among husbands and wives wanting no more children; about $64 \%$ of husbands and $46 \%$ of wives who were using contraceptives and wanted no more children responded 


\begin{tabular}{|c|c|c|c|}
\hline \multirow{2}{*}{$\begin{array}{l}\text { Contraceptive use and } \\
\text { wife's pregnancy attitude }\end{array}$} & \multicolumn{2}{|c|}{ Husband's report } & \multirow[b]{2}{*}{ All } \\
\hline & $\begin{array}{l}\text { Any } \\
\text { problem }\end{array}$ & $\begin{array}{l}\text { No } \\
\text { problem }\end{array}$ & \\
\hline \multicolumn{4}{|l|}{ USERS $(\mathrm{N}=3,085)^{* *}$} \\
\hline \multicolumn{4}{|l|}{ Wife's report } \\
\hline All & 30.0 & 70.0 & 100.0 \\
\hline Any problem & 20.7 & 25.7 & 46.4 \\
\hline No problem & 9.3 & 44.3 & 53.6 \\
\hline \multicolumn{4}{|l|}{$64 \%$ agreement (Kappa statistic, 0.26 ) } \\
\hline \multicolumn{4}{|l|}{ NONUSERS $(\mathrm{N}=750)^{*}$} \\
\hline \multicolumn{4}{|l|}{ Wife's report } \\
\hline All & 32.6 & 67.4 & 100.0 \\
\hline Any problem & 20.4 & 31.4 & 51.8 \\
\hline No problem & 12.2 & 36.0 & 48.2 \\
\hline $61 \%$ agreement (Kappa statistic, 0.24 ) & & & \\
\hline
\end{tabular}

that becoming pregnant soon would be no problem.

Among nonusers, individuals who wanted to delay a birth two or more years or stop childbearing responded to the problem question in a way that was contrary to their contraceptive behavior. Among couples who did not use contraceptives, $80 \%$ of men who wanted to delay two or more years and $62 \%$ who did not want any more children said that their wife's becoming pregnant soon would be no problem for them; the corresponding figures for wives were $70 \%$ and $46 \%$, respectively.

Examination of couple concordance on reported contraceptive use and fertility desires were undertaken (not shown). Concordance on contraceptive use was substantial, with 90\% agreement and a Kappa statistic of 0.73 . Concordance on not wanting any more children was also high, with $82 \%$ agreement and a Kappa statistic of 0.62 . (Though most couples agreed, $70 \%$ of the disagreement between spouses came in couples in which the husband wanted more children, while the wife wanted to stop childbearing.)

We performed a cross-tabulation of husbands' and wives' responses to the problem question for couples who wanted to stop childbearing or to delay a birth for two or more years; the cross-tabulation is presented separately for contraceptive-using and -nonusing couples (Table 4). Concordance on the problem question was lower on contraceptive use and fertility desires: There was 64\% agreement among contraceptive users (Kappa statistic, 0.26) and $61 \%$ agreement among couples who did not use contraceptives (0.24). In both groups, about $20 \%$ of couples agreed that a pregnancy would be a big or small problem, while $44 \%$ of users and $36 \%$ of nonusers agreed that a pregnancy would be no problem. The overall level of agreement between the two groups was similar; discordance occurred mainly in couples in which the husband reported no problem and the wife reported either a big or small problem. This type of discordance accounted for
$26 \%$ of couples using contraceptives and $31 \%$ of their nonusing counterparts. The $36 \%$ of couples who did not use contraceptives although they wanted to delay or stop childbearing and who agreed that an unexpected pregnancy would be no problem for them would seem to be the group of nonusers (typically labeled as having an unmet need) least likely to adopt contraception. In summary, pregnancy ambivalence appears to be high in this population, while shared pregnancy ambivalence is relatively low. Discordance on the issue is mainly because husbands more frequently reported a pregnancy would be no problem than their wives.

\section{Multivariate Analysis}

In a multivariate regression run on the subset of couples in which at least one partner expressed a desire to delay or stop childbearing, contraceptive use was associated with the woman being $25-34$ years old (odds ratio, 2.2), having education (2.0-2.5), having three or fewer births (1.9-2.0) or living in Java (1.4; Table 5). After demographic factors were controlled for, couples' ambivalence about pregnancy was associated with contraceptive use. In par-

\begin{tabular}{|c|c|}
\hline Variable & Odds ratio \\
\hline \multicolumn{2}{|l|}{ Age } \\
\hline $15-24$ & $1.55 \dagger$ \\
\hline $25-34$ & $2.20^{* *}$ \\
\hline 35-49 (ref) & 1.00 \\
\hline \multicolumn{2}{|l|}{ Education } \\
\hline None (ref) & 1.00 \\
\hline Primary & $1.98^{*}$ \\
\hline zsecondary & $2.51^{* *}$ \\
\hline \multicolumn{2}{|l|}{ No. of children ever born } \\
\hline $0-1$ & $1.91^{*}$ \\
\hline $2-3$ & $1.96^{* *}$ \\
\hline$\geq 4$ (ref) & 1.00 \\
\hline \multicolumn{2}{|l|}{ Household wealth } \\
\hline Poorer & 0.78 \\
\hline Middle (ref) & 1.00 \\
\hline Wealthier & 0.90 \\
\hline \multicolumn{2}{|l|}{ Region } \\
\hline Java & $1.38^{* *}$ \\
\hline All others (ref) & 1.00 \\
\hline \multicolumn{2}{|l|}{ Couple's pregnancy ambivalence } \\
\hline Only one partner ambivalent & $0.74^{*}$ \\
\hline Both partners ambivalent & 0.98 \\
\hline Neither partner ambivalent (ref) & 1.00 \\
\hline \multicolumn{2}{|l|}{ Couple's fertility desires } \\
\hline One partner wants to delay, other wants to stop & 0.70 \\
\hline $\begin{array}{l}\text { One partner wants to delay or stop, other wants } \\
\text { more or is undecided }\end{array}$ & $0.42^{* *}$ \\
\hline Both partners want to delay & 0.79 \\
\hline Both partners want to stop (ref) & 1.00 \\
\hline McFadden's pseudo $R^{2}=0.0779$ & \\
\hline
\end{tabular}


ticular, the odds of use among discordant couples (one partner was ambivalent; the other was not) were 26\% lower than those among couples in which neither partner was ambivalent (both reported that it would be a small or big problem if a pregnancy occurred). For comparison, the full model was run (not shown) with separate variables for discordant ambivalence (wife ambivalent, husband not; wife not ambivalent, husband ambivalent). Discordance was marginally significant at $\mathrm{p} \leq .10$ : When the husband was ambivalent and the wife was not, the odds ratio for contraceptive use was $0.8(p=.10)$, and when the wife was ambivalent and the husband was not, the odds ratio was 0.7 ( $p=.09$ ). Having discordant fertility desires was associated with lower odds of contraceptive use than agreement about not wanting any more children. The odds of using contraceptives decreased by $58 \%$ for couples in which one partner wanted to delay or stop childbearing while the other wanted more children or was undecided compared with couples in which both partners wanting to stop. The pseudo R-squared for the regression is 0.0779 , indicating a minimal difference between the log likelihoods of the null and full model; however, the pseudo Rsquared should be interpreted with caution as multiple models to fit the data were not conducted (variables were selected on the basis of theory).

\section{DISCUSSION}

This study examines pregnancy ambivalence among couples in Indonesia, taking advantage of a survey question on whether a pregnancy in the next few weeks would be perceived as a big problem, a small problem or no problem. By including husbands in the analysis, this study is one of the first to examine pregnancy ambivalence as a couple issue, rather than solely as a woman's issue. The results of the analysis support the assertion that husbands' fertility desires and attitudes about pregnancy are important influences on contraceptive use.

The analyses show that in 2002-2003, a large percentage of husbands and wives in Indonesia felt that an unexpected pregnancy in the next few weeks would present no problem, even among those who reported that they wanted to delay or stop childbearing. The percentage of this subgroup who said a pregnancy would be no problem was high for both husbands and wives, though the level for husbands was particularly high (seven of every 10). More than half of all wives in this subgroup also said a pregnancy would be no problem, a level much higher than that expressed by women in other countries in which this question has been analyzed. An analysis of Demographic and Health Survey data from Burkina Faso, Ghana and Kenya found that fewer than $30 \%$ of women who wanted to delay or limit childbearing reported that a pregnancy in the next few weeks would be no problem. ${ }^{2}$ These cross-country differences cannot be explained with the data available, although the Indonesia findings suggest gender differences in attitudes toward unexpected pregnancy. Furthermore, cross-country variation in levels of ambivalence may be re- lated to the countries being in different stages of fertility transition.

Interestingly, no difference in contraceptive use appeared between couples in which both partners expressed pregnancy ambivalence and couples in which neither partner expressed ambivalence. This suggests that for couples in which at least one partner expresses a need to delay or stop childbearing and both partners express pregnancy ambivalence, the decision to use or not use contraceptives may be based on factors other than the desire to avoid a pregnancy (for example, attitudes toward the use of contraceptives). ${ }^{3}$ Qualitative research is needed to explore this issue in greater depth.

Like most studies of this type, this research has limitations that need to be recognized. One weakness of this study is that the measure of pregnancy ambivalence, which was based on a combination of responses to questions on fertility preferences and the problem question, might not actually capture ambivalence as we have defined it. The term "problem" used in the problem question is broad and could be understood to represent a variety of issues, such as problems related to physical health (i.e., the ability to have a healthy pregnancy) or even economic well-being (i.e., the financial ability to care for a child). Responses that are based on such interpretations may not fully reflect the degree of trouble or difficulty that an unexpected pregnancy may cause. In addition, it is not known whether there are gender and cultural differences in the interpretation of and reaction to the problem question.

Another weakness of the study is that couple-level demographic variables for age, education and parity were not used in the multivariate analysis; the women's variables were used instead. We chose to use women's demographic characteristics because there was high collinearity between women's and men's demographic characteristics; the men's variables (or the joint variables) would not have contributed significantly. Women's reported contraceptive use was also used rather than a joint contraceptive-use variable, because of the high concordance in reports. When there were differences, women were somewhat more likely to report contraceptive use than men. Though wife's use does include her husband's use of condoms within their relationship, results might have differed slightly if a dependent variable for contraceptive use as reported by both partners had been used.

This analysis also did not examine levels of ambivalence by type of contraceptive method used. For example, there may be differences between users of reversible and permanent methods. Though one would expect users of permanent methods to have solidly nonambivalent attitudes about future pregnancies, there may be differences by reversible method as well. Variations in ambivalence by type of contraceptive method used in Indonesia is a potential area for future research.

We were interested to find few differences between current contraceptive users and nonusers in the distribution of their responses to the problem question. In this sample, 
a large percentage of contraceptive users, like their nonusing counterparts, did not consider a pregnancy in the next few weeks to be a problem. Such attitudes may make effective use and continuation less likely for these couples, especially if they experience side effects or service barriers while using a method. Additional research is needed to determine whether this finding holds true for all users and nonusers. This finding also suggests that many couples identified as having an unmet need are not highly motivated to adopt contraception. Unfortunately, with the available data, we are not able to examine how use of abortion (or attitudes toward abortion) influences this level of ambivalence. Conversely, almost half of wives and one-third of husbands not using contraceptives said that a pregnancy in the next few weeks would be a big or small problem; this group should be targeted by family planning programs, as they have a clear unmet need for family planning. This targeting could happen through primary care facilities or through community-based programs that include a screening module to determine if women (and men) have a nonambivalent unmet need for family planning.

Indonesian couples whose attitudes about pregnancy and fertility desires were in agreement were more likely to be using contraceptives than couples whose attitudes and desires were discordant. This finding suggests that the attitudes and desires of both partners influence contraceptive use. The finding supports previous research that found Indonesian women's choice of method, when to start and when to switch is often influenced by their husbands. ${ }^{18,30}$ Our findings suggest a need for relationshipcentered reproductive health and family planning programs, especially in settings like Indonesia, in which husbands play an important decision-making role. ${ }^{30}$ Family planning program providers seeking to improve effective use or continuation of use in Indonesia should take couples' pregnancy attitudes into account at the time of screening and method selection.

This study demonstrates the utility of using couple-level data to examine factors associated with contraceptive use, in Indonesia and generally. In particular, the finding that discordant couples were less likely to use contraceptives indicates the importance of understanding both husbands' and wives' fertility and family planning attitudes and intentions when seeking to identify the determinants of contraceptive use. Future studies should seek to include couples whenever feasible; this will further improve our knowledge of barriers to effective and consistent contraceptive use as well as to other reproductive health services.

In Indonesia, given that husbands were more accepting of an unexpected pregnancy, additional research is needed to better understand men's motivations for using and not using family planning. Such knowledge is important, as men are currently being targeted for greater participation in family planning in Indonesia, and some programs are seeking to implement a couple-centered approach. ${ }^{31}$ More detailed information from men and couples on their fertility desires should be used to improve family planning programs to ensure that programs are designed to meet the needs of all couples in Indonesia.

\section{REFERENCES}

1. Trussell J, Vaughan B and Stanford J, Are all contraceptive failures unintended pregnancies? Evidence from the 1995 National Survey of Family Growth, Family Planning Perspectives, 1999, 31(5):246-247 \& 260

2. Speizer I, Using strength of fertility motivations to identify family planning program strategies, International Family Planning Perspectives, 2006, 32(4):185-191.

3. Zabin LS, Ambivalent feelings about parenthood may lead to inconsistent contraceptive use-and pregnancy, Family Planning Perspectives, 1999, 31(5):250-251.

4. Bachrach CA and Newcomer S, Intended pregnancies and unintended pregnancies: distinct categories or opposite ends of a continuum? Family Planning Perspectives, 1993, 31(5):251-252.

5. Santelli J et al., The measurement and meaning of unintended pregnancy, Perspectives on Sexual and Reproductive Health, 2003, 35(2):94-101

6. Williams L, Sobieszczyk T and Perez AE, Consistency between survey and interview data concerning pregnancy wantedness in the Philippines, Studies in Family Planning, 2001, 32(3):244-253.

7. Bruckner H, Martin A and Bearman PS, Ambivalence and pregnancy: adolescents' attitudes, contraceptive use and pregnancy, Perspectives on Sexual and Reproductive Health, 2004, 36(6):248-257.

8. Crosby RA et al., Adolescents' ambivalence about becoming pregnant predicts infrequent contraceptive use: a prospective analysis of nonpregnant African American females, American Journal of Obstetrics E Gynecology, 2002, 186(2):251-252.

9. Frost JJ, Singh $S$ and Finer LB, Factors associated with contraceptive use and nonuse, United States, 2004, Perspectives on Sexual and Reproductive Health, 2007, 39(2):90-99.

10. Schunmann C and Glasier A, Measuring pregnancy intention and its relationship with contraceptive use among women undergoing therapeutic abortion, Contraception, 2007, 73(5):520-524.

11. Schwartz EB et al., Prevalence and correlates of ambivalence towards pregnancy among nonpregnant women, Contraception, 2007, 75(4):305-310

12. Curtis SL and Blanc AK, Determinants of contraceptive failure, switching, and discontinuation: an analysis of DHS contraceptive histories, DHS Analytical Reports, Calverton, MD, USA: Macro International, 1997, No. 6.

13. Kost $\mathrm{K}$ et al., Estimates of contraceptive failure from the $2002 \mathrm{Na}-$ tional Survey of Family Growth, Contraception, 2008, 77(1):10-21.

14. Jones RK, Darroch JE and Henshaw SK, Contraceptive use among U.S. women having abortions in 2000-2001, Perspectives on Sexual and Reproductive Health, 2002, 34(6):294-303.

15. Jaccard J, Dodge T and Dittus P, Do adolescents want to avoid pregnancy? Attitudes toward pregnancy as predictors of pregnancy, Journal of Adolescent Health, 2003, 33(2):79-83.

16. Westoff CF and Bankole A, The time dynamics of unmet need: an example from Morocco, International Family Planning Perspectives, 1998, 24(1):12-14 \& 24.

17. Joesoef MR, Baughman AL and Utomo B, Husband's approval of contraceptive use in metropolitan Indonesia: program implications, Studies in Family Planning, 1988, 19(3):162-168.

18. Amal SH et al., Family Planning and Women's Empowerment: Chat lenges for the Indonesian Family, Final Report Prepared for the Women's Studies Project, Research Triangle Park, NC, USA: Family Health International, 1997.

19. Ezeh AC, The influence of spouses over each other's contraceptive attitudes in Ghana, Studies in Family Planning, 1993, 24(3):163-174.

20. Dodoo FNA, Men matter: additive and interactive gendered preferences and reproductive behavior in Kenya, Demography, 1998, 
35(2):229-242.

21. Speizer IS, Are husbands a barrier to women's family planning use? The case of Morocco, Social Biology, 1999, 46(1-2):1-16.

22. DeRose LF and Ezeh AC, Men's influence on the onset and progress of fertility decline in Ghana, 1988-98, Population Studies, 2005, 59(2):197-210.

23. Hossain MB, Phillips JF and Mozumder AB, The effect of husbands' fertility preferences on couples' reproductive behaviour in rural Bangladesh, Journal of Biosocial Science, 2007, 39(5):745-757.

24. Ezeh AC, Seroussi M and Raggers H, Men's fertility, contraceptive use, and reproductive preferences, DHS Comparative Studies, Calverton, MD, USA: Macro International, 1996, No. 18.

25. United Nations Population Fund (UNFPA), Population data for development: Indonesia, 2003, <http://indonesia.unfpa.org/ Population\%20Data\%20for\%20Development.htm>, accessed Mar. 27, 2009.

26. Badan Pusat Statistik-Statistics Indonesia (BPS) and ORC Macro, Indonesia Demographic and Health Survey 2002-2003, Calverton, MD, USA: BPS and ORC Macro, 2003.

27. Central Bureau of Statistics et al., Indonesia Demographic and Health Survey 1991, Columbia, MD, USA: Macro International, 1992.

28. United Nations, Abortion Policies: A Global Review, Indonesia, 2002, <http://www.un.org/esa/population/publications/abortion/ profiles.htm>, accessed Mar. 27, 2009.

29. Landis JR and Koch GG, The measurement of observer agreement for categorical data, Biometrics, 1977, 33(1):159-174.

30. Sciortino R, The challenge of addressing gender in reproductive health programmes: examples from Indonesia, Reproductive Health Matters, 1998, 6(11):33-44.

31. UNFPA Indonesia, Reproductive health and reproductive rights, 2003, <http://indonesia.unfpa.org/rr.htm>, accessed Mar. 27, 2009.

\section{RESUMEN}

Contexto: La mayoría de los estudios sobre actitudes de ambivalencia ante el embarazo se basan en datos provenientes de mujeres y dependen de las percepciones de las mujeres para medir las intenciones de su pareja respecto al embarazo. Debido a que estas percepciones pueden no ser exactas, es necesario recolectar datos provenientes directamente de hombres para comprender el rol de las dinámicas de pareja en el comportamiento referente a la fecundidad.

Método: Se utilizaron datos pareados de parejas provenientes de la Encuesta de Demografía y Salud de Indonesia 20022003 para examinar el uso de anticonceptivos, los deseos de fecundidad y las actitudes respecto a embarazarse en las próximas semanas-preguntando si esto sería un problema grande, un problema pequeño o no sería un problema. Se evaluó la concordancia entre los miembros de la pareja. Los deseos inconsistentes de fecundidad y las respuestas a la pregunta planteada se usan para definir la ambivalencia dentro de las parejas. Se usó análisis de regresión logística multivariada para evaluar si la ambivalencia de las parejas respecto al embarazo estaba asociada al uso de anticonceptivos.

Resultados: Setenta y un por ciento de los esposos y $54 \%$ de las esposas informaron que un embarazo en las siguientes semanas "no sería un problema"; la concordancia de las parejas respecto a esta pregunta fue de $64 \%$ entre usuarios de anticonceptivos y $61 \%$ entre no usuarios. En el análisis multivariado, las parejas que fueron discordantes en el tema de un embarazo en el futuro próximo tuvieron $26 \%$ menor probabilidad de usar anticonceptivos que las parejas en las que ambos miembros estuvieron de acuerdo en que un embarazo sería un problema grande o pequeño. El uso de anticonceptivos también fue menos probable en las parejas en las que uno de sus miembros deseaba retrasar o ya no tener hijos y el otro deseaba más hijos o estaba indeciso (0.4).

Conclusiones: Los esposos y las esposas se influyen mutuamente en las actitudes respecto a la fecundidad y el uso de planificación familiar. Las actitudes respecto al embarazo tanto de los esposos como de las esposas deben tomarse en cuenta en el momento del tamizaje y la selección de método.

\section{RÉSUMÉ}

Contexte: La plupart des études sur l'ambivalence à l'égard de la grossesse reposent sur les données obtenues auprès des femmes et dépendent de leurs perceptions pour la mesure des intentions de grossesse de leurs partenaires. Ces perceptions ne sont pas toujours exactes et il importe de collecter les données directement auprès des hommes si l'on veut mieux comprendre le rôle de la dynamique du couple dans les comportements de fécondité.

Méthode: Les données de couple de l'Enquête démographique et de santé indonésienne de 2002-2003 servent à examiner la pratique contraceptive, les désirs de fécondité et les attitudes concernant la perspective d'une grossesse durant les quelques semaines suivantes: la situation poserait-elle un gros problème, un petit problème ou pas de problème du tout? La concordance entre les partenaires est évaluée. Les désirs inconsistants de fécondité et les réponses à la question du problème servent à définir l'ambivalence au sein des couples. L'association entre l'ambivalence des couples vis-à-vis de la grossesse et la pratique contraceptive est évaluée par analyse de régression logistique multivariée.

Résultats: Selon $71 \%$ des maris et $54 \%$ des épouses, une grossesse survenant durant les quelques semaines suivantes ne poserait «aucun problème». La concordance des couples sur cette question est de 64\% parmi ceux qui pratiquent la contraception et de $61 \%$ parmi ceux qui ne la pratiquent pas. Au niveau de l'analyse multivariée, les couples discordants sur la question d'une prochaine grossesse présentent une probabilité moindre de $26 \%$ de pratiquer la contraception, par rapport à ceux dont les deux partenaires conviennent qu'une grossesse représenterait un gros ou un petit problème. La pratique contraceptive est aussi moins probable au sein des couples dont un partenaire désire différer ou arrêter la procréation et l'autre désire encore des enfants ou est indécis sur la question $(0,4)$.

Conclusions: Le mari et la femme influencent les attitudes de fécondité l'un de l'autre et la pratique de la planification familiale. Les attitudes des deux vis-à-vis de la grossesse doivent être prises en compte lors de l'évaluation et de la sélection d'une méthode.

\section{Acknowledgments}

This work was supported by the U.S. Agency for International Development (USAID) under the terms of Cooperative Agreement GPO-A-00-03-00003-00. The authors' views do not necessarily reflect the views of USAID or the U.S. government.

Author contact: bardenof@email.unc.edu 